\title{
Alteração da superfície de velas cerâmicas porosas comerciais, por processo sol-gel, visando o aumento da organofilicidade
}

\section{(Changes on surface of commercial ceramic filtration candles, via sol-gel, aiming at an increase in organophilicity)}

\author{
C.R.Alves ${ }^{1}$, O.B.G.Assis ${ }^{2}$ \\ ${ }^{1}$ Departamento de Química, Universidade Estadual do Ceará, Av. Paranjana 1700, Fortaleza, CE 60740-903 \\ ${ }^{2}$ Embrapa Instrumentação, Rua XV de Novembro 1452, S. Carlos, SP 13560-970 \\ alvescr@pq.cnpq.br,odilio@cnpdia.embrapa.br
}

\begin{abstract}
Resumo
Velas cerâmicas empregadas para a filtração doméstica de água consistem de elementos porosos sinterizados a base de aluminossilicatos com larga distribuição de tamanhos de poros e grãos. Esses filtros têm se mostrado úteis na retenção de micropartículas em suspensão por exclusão de tamanhos, mas apresentam baixa eficiência com respeito à remoção de compostos químicos e de micro-organismos. Para elevar sua capacidade de filtração, principalmente de contaminantes orgânicos, alterações superficiais foram conduzidas fazendo uso de revestimento de $\mathrm{SiO}_{2}$ pela técnica de sol-gel dip-coating. Análises indicam que o filme de $\mathrm{SiO}_{2}$ obtido por calcinação gera uma redução média de 3,5 $\mu \mathrm{m}$ nos tamanhos de poros causando uma ligeira queda de pressão na permeação, contudo, a superfície vítrea melhora a organofilicidade elevando a eficiência de remoção de bactérias, principalmente para vazões em baixo fluxo.
\end{abstract}

Palavras-chave: sol-gel, $\mathrm{SiO}_{2}$, velas cerâmicas, filtração, sinterização, remoção de bactérias.

\section{Abstract}

Water household ceramic filter candles are sintered porous elements based on aluminosilicates and characterized by having a large distribution of pores and grain sizes. Such filters are useful in the retention of microparticles in suspension by size exclusion; however they present low efficiency in microorganism and chemical contaminants removals. In order to increase its filtration capability, mainly concerning organic contaminants, surface modifications were conducted by $\mathrm{SiO}_{2}$ sol-gel dip-coating. Analysis revels that after $\mathrm{SiO}_{2}$ film densification an average reduction in $3.5 \mu \mathrm{m}$ in pore size is measured what generates a slight decay permeation pressure. Nevertheless, the vitreous surface enhances the organofilicity increasing the bacteria removal efficiency, mainly at low permeation flux.

Keywords: sol-gel, $\mathrm{SiO}_{2}$, ceramic filtration candles, filtration, sintering, bacteria removal.

\section{INTRODUÇÃO}

A qualidade da água destinada ao consumo humano é sem dúvida um dos aspectos mais importantes no que diz respeito à saúde de um país. $\mathrm{O}$ acesso à água potável e a proporcional quantidade de tratamento de águas residuárias consistem em índices comparativos de desenvolvimento adotados pela Organização Mundial da Saúde (OMS) [1]. Segundo a própria OMS, o consumo de águas contaminadas ou não tratadas tem sido responsável por 2 milhões de mortes por ano no mundo [2]. No Brasil cerca de $80 \%$ das doenças e $65 \%$ do total das internações anuais, estão relacionados com a água [3], sendo as principais incidências a disenteria bacilar, o cólera, a febre tifoide, a febre paratifoide, a gastrenterite, a diarreia infantil, a esquistossomose e a leptospirose, vindo em seguida, contaminações por poluentes químicos e impurezas de origens diversas. Embora o Brasil encontrase em uma situação privilegiada por possuir em torno de $13 \%$ de toda água doce do mundo [4], o seu tratamento e acesso é bastante irregular, com marcantes diferenças regionais [5]. Para melhorar a qualidade da água consumida, principalmente nas zonas urbanas, é comum a população fazer uso de filtros domésticos, com o objetivo de assegurar uma limpeza mínima, barata e "in loco" da água a ser consumida. O sistema mais empregado no Brasil consiste de uma talha cerâmica na qual geralmente o meio filtrante é um cartucho de porcelana porosa (ou de materiais similares), com uma das extremidades vedada denominada "vela de Lambreth" ou simplesmente "vela". Essas velas têm dimensões variadas, podendo apresentar ou não carvão ativado em seu interior ou prata coloidal em sua superfície. Através delas a água flui em diversas vazões, sob a ação da pressão exercida pela própria coluna de água dentro da talha. Uma vela comercial padrão é composta de uma mistura de alumina e argila apresentando poros de dimensões que variam, dependendo do processo de fabricação, de 1 a $50 \mu \mathrm{m}$. Embora de largo espectro, essa distribuição de tamanhos nem sempre interrompem a passagem da totalidade dos contaminantes presentes na 
água. As velas cerâmicas apresentam boa ação em reter por "peneiramento" micro ou macropartículas em suspensão reduzindo da turbidez do meio [6]. Contudo, compostos químicos, inclusive orgânicos, agrotóxicos e a maioria dos micro-organismos, apresentam dimensões menores que $1,0 \mu \mathrm{m}$ e podem assim transitar livremente por entre os poros de uma vela comercial [7]. Uma possível melhora na capacidade de retenção, sem perdas no fluxo permeado, pode ser conseguida pelo aumento da organofilicidade superficial do elemento filtrante.

Existem diversas possibilidades para incrementar a afinidade por compostos orgânicos de uma cerâmica, sendo a mais eficiente o aumento da disponibilidade de grupos do tipo silanois/hidroxilas $(\mathrm{SiOH})$ e siloxanos $\left(\mathrm{SiO}^{-}\right)$na superfície [8], o que pode ser conseguido pela deposição de uma fina camada de $\mathrm{SiO}_{2}$ via processo sol-gel. Este é um processo relativamente simples e já vem sendo empregado sobre próteses com o objetivo de elevar a biocompatibilidade de implantes cirúrgicos $[9,10]$.

Neste trabalho, o efeito de um revestimento de $\mathrm{SiO}_{2}$, processado via sol-gel, é avaliado com o objetivo de elevar a organofilicidade de uma vela cerâmica comercial, caracterizando as alterações em sua estrutura e efeitos sobre a remoção de bactérias em meio aquoso.

\section{MATERIAIS E MÉTODOS}

\section{Caracterização das velas comerciais}

Velas de origem comercial de marca popular foram adquiridas no comércio local. Amostras circulares, com diâmetro próximo a $2,0 \mathrm{~cm}$ e parede com espessuras próximas a $1,0 \mathrm{~cm}$, foram removidas de diversas posições e encaminhadas para análises. A microestrutura foi avaliada por meio de fotomicrografias obtidas pelo microscópio eletrônico de varredura LEO 1430 com microanálises por EDX (Link Analytical QX-2000). A distribuição de tamanhos de poros foi obtida por porosimetria por intrusão de mercúrio (PoreSizer 9230, Micromeritics) e medidas de permeabilidade foram realizadas em sistema de queda de pressão em câmara cilíndrica com fluxo perpendicular a amostra, segundo montagem descrita em $[11,12]$. Os principais óxidos constituintes das velas foram identificados por difração de raios X (radiação Cuka) em difratômetro Shimadzu, XRD 6000.

\section{Deposição por sol-gel}

Para a alteração das condições superficiais empregouse a técnica de sol-gel para a polimerização de uma fina camada vítrea ao redor dos poros. Embora a composição da vela cerâmica tenha por base estruturas de $\mathrm{Si}$, este está presente em volume insuficiente para o acoplamento estável de compostos orgânicos por simples adsorção [13]. Para a deposição do filme empregamos solução precursora de $\mathrm{SiO}_{2}$ preparada a partir de $\mathrm{Si}\left(\mathrm{OCH}_{3}\right)_{4}$ (tetrametoxisilano, TMOS da Fluka) diluído em metanol $\mathrm{H}_{3} \mathrm{COH}$ (Merck) e ácido

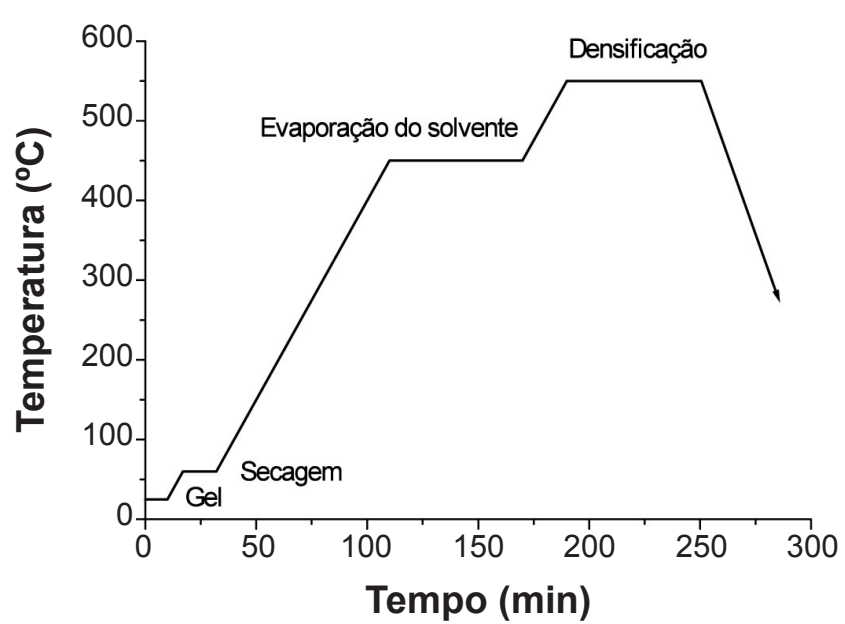

Figura 1: Ciclo térmico aplicado para a densificação de depósito de $\mathrm{SiO}_{2}$ via sol-gel.

[Figure 1: Thermal cycle applied for sol-gel $\mathrm{SiO}_{2}$ film formation.]

fórmico $\mathrm{HCOOH}$ (Mallinckrodt), na proporção de 1:1:0,1 por volume. A mistura foi submetida a ultrassom por 20 min para favorecer uma melhor uniformidade e acelerar a hidrólise [14].

Os filmes foram depositados por imersão controlada (dip coating) sobre as amostras removidas do corpo das velas. A velocidade de imersão e retirada foi estabelecida em 10 $\mathrm{cm} / \mathrm{min}$. As amostras eram previamente limpas com acetona antes dos depósitos. A densificação da deposição seguiu sequência convencionalmente empregada em processos solgel, ou seja, secagem a $60{ }^{\circ} \mathrm{C}$ por 15 min ${ }^{\circledR}$ eliminação de solvente a $450{ }^{\circ} \mathrm{C}(1 \mathrm{~h}){ }^{\circledR}$ calcinação final a $550{ }^{\circ} \mathrm{C}(1 \mathrm{~h})$. Este ciclo está ilustrado na Fig. 1. A taxa de aquecimento e resfriamento foi a mesma $\left(5^{\circ} \mathrm{C} / \mathrm{min}\right)$ em todas as etapas. A densificação foi conduzida ao ar e as amostras resfriadas ao forno evitando assim choque térmico.

\section{Caracterização após o revestimento e filtração}

Além da porosimetria, avaliação da permeabilidade, MEV e difração de raios X como realizados no substrato, as amostras com e sem deposição foram submetidas a ensaios de filtração em coluna de permeação. Os testes foram conduzidos em meio com bactérias gran-negativa Escherichia coli (JM109) em suspensão como modelo de contaminação. Cepa das bactérias foram adquiridas da Fundação Tropical André Tosello (Campinas, Brasil) e crescidas em meio nutriente (Agar sintético, $\mathrm{pH} 7,5$ ) em condições de anaerobiose e agitação moderada a $37{ }^{\circ} \mathrm{C}$ segundo procedimento padrão [15]. Os testes de filtragem foram conduzidos por passagem de solução contaminada em uma coluna simples de 1 polegada de diâmetro especialmente elaborada para este fim. A área de permeação foi próxima a $5 \mathrm{~cm}^{2}$. As medidas foram realizadas em triplicata, para diferentes vazões até o maior fluxo possível em função da coluna de água (altura de $45 \mathrm{~cm}$ ). As bactérias foram dispersas em meio aquoso e a eficiência de filtragem avaliada com base nas diferenças de medidas proporcionais 
de bactérias coletadas no afluente e efluente, através de medida de densidade óptica (turbidez) em espectrômetro UV-VIS Shimadzu UV-1661PC no comprimento de onda de $600 \mathrm{~nm}$ (região do visível) sendo os resultados expressos em absorbância. Detalhes da metodologia podem ser encontrados em $[16,17]$. A eficiência de remoção foi calculada com base na relação apresentada em [18], com modificações, ou seja:

$$
\% \text { Removida }=\left(\mathrm{Ab}_{\mathrm{afl}}-\mathrm{Ab}_{\mathrm{eff}}\right) / \mathrm{Ab}_{\mathrm{afl}} \times 100
$$

sendo $A b_{\text {afl }}$ e $A b_{\text {efl }}$ as absorbâncias relativas às densidades óticas de bactérias medidas em suspensão no afluente e efluente respectivamente.

\section{RESULTADOS E DISCUSSÃO}

\section{Organofilicidade superficial}

Uma importante característica de um material para emprego como meio filtrante, além de sua permeação por exclusão de tamanhos, é sua organofilicidade que pode ser definida como a afinidade de uma superfície a interações com compostos de origem orgânica. O grau de organofilicidade pode ser medido e alterado tornando-se assim o material seletivo a certos tipos de compostos, que tenham uma atividade bioquímica específica ou afinidade a certos tipos de micro-organismos agindo como suporte a sua fixação. Uma superfície com razoável organofílicidade deve apresentar boa molhabilidade, além de dispor de uma grande densidade de cargas na superfície, favorecendo a adsorção de grupos do tipo $\mathrm{O}^{-} \mathrm{H}^{+}$ou demais moléculas catiônicas, típicas de biomateriais [5]. Este incremento na organofilicidade pode ser conseguido, como já comentado, pelo aumento da densidade de átomos de Si na superfície e consequente formação de sítios silanóis ativos $[8,19,20]$.

\section{Modificações superficiais por sol-gel}

A técnica de sol-gel permite a preparação de filmes vítreos de espessuras diversas e com alta pureza. O processo é bastante estudado e basicamente consiste na transição de uma dispersão para um sistema gel, seguido pela "polimerização" de uma estrutura rígida a partir de partículas coloidais. Três reações básicas envolvem o processo que são a hidrólise, a condensação e a decomposição térmica [21]. Essas reações, utilizando um alcóxido metálico como precursor, podem ser expressas por [22]:

$$
\begin{aligned}
& \mathrm{Si}(\mathrm{OR})_{4}+\mathrm{nH}_{2} \mathrm{O} \rightarrow \mathrm{Si}(\mathrm{OH})_{4 \mathrm{n}}(\mathrm{OH})_{\mathrm{n}}+\mathrm{nROH} \\
& \equiv \mathrm{Si}-\mathrm{OH}+\mathrm{HO}-\mathrm{Si} \equiv \rightarrow \equiv \mathrm{Si}-\mathrm{O}-\mathrm{Si} \equiv+\mathrm{H}_{2} \mathrm{O} \\
& \mathrm{Si}-(\mathrm{OH})+\mathrm{M}-(\mathrm{OH}) \rightarrow \mathrm{Si}-\mathrm{O}-\mathrm{M}^{+} \mathrm{H}_{2} \mathrm{O}
\end{aligned}
$$

que experimentalmente correspondem as etapas de preparação da solução de partida (sol) pela hidrólise do grupo alcóxido (OR) com formação de grupos hidroxila $(\mathrm{OH})$; de gelificação, pela condensação do grupo silanol (Si$\mathrm{OH})$ e, do ciclo térmico (densificação). $\mathrm{O}$ aquecimento do gel resulta na sinterização e coalescimento das partículas de óxido do metal presente no composto precursor.

\section{Caracterização fisica}

Vemos pelos difratogramas de raios X (Fig. 2) que após a calcinação do revestimento predominam padrões de difrações identificadas como estruturas à base de silicatos com visível redução daquelas correspondentes aos óxidos de alumínio e aluminossilicatos. Embora os filmes sol-gel de $\mathrm{SiO}_{2}$ produzidos por dip-coating, em única imersão, geralmente não apresentem espessuras superiores a $1 \mu \mathrm{m}$ [23], estas são suficientes para que as difrações resultantes sobreponham as difrações originais do substrato (vela).

A formação de uma cobertura vítrea contínua ao longo de toda a superfície da vela é confirmada por observações microscópicas (Fig. 3). Comparando o aspecto superficial anterior e após o processo fica evidente a formação de um filme denso com significativas alterações superficiais como a rugosidade e a porosidade.

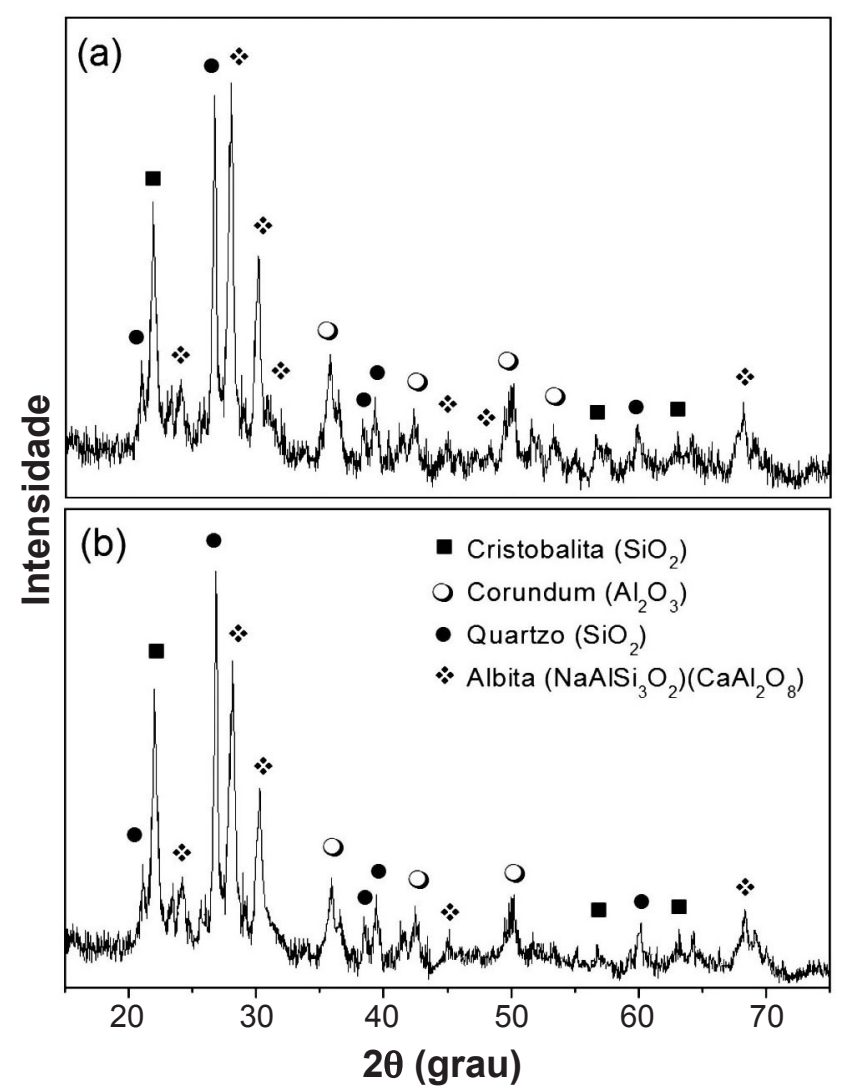

Figura 2: Difratogramas de raios X (a) de uma vela cerâmica comercial padrão e (b) após a densificação de filme vítreo superficial. Os picos identificam as fases que compõem o material. Radiação Cuk $\alpha$.

[Figure 2: XRD patterns of a standard commercial filtration candle (a) and after the vitreous coating densification (b). The peaks identify the constituent with phases. Cuk $\alpha$ radiation.] 
Vemos que a estrutura original da vela (Fig. 3a) é caracterizada por uma sinterização incipiente de aglomerados de partículas de tamanhos diversos e formatos irregulares, resultando em uma matriz de baixa densidade e dimensões variadas de poros. A imersão na solução provoca a permeação do gel na estrutura com preenchimento de uma grande fração dos poros de menor diâmetro. Após o ciclo térmico, temos a densificação do filme superficial gerando uma estrutura de maior densidade, com superfície externa predominantemente vítrea. Análises adicionais fornecem indícios da composição do vidro formado, Fig. 4, onde estão apresentados os espectros de EDX que permitem acompanhar a variação das concentrações dos elementos na superfície.

O efeito da deposição sobre os tamanhos de poros fica evidenciado pelas medidas de porosimetria por intrusão de mercúrio, indicando uma redução numérica nos valores médios de diâmetros de $15,2 \mu \mathrm{m}$ na vela comercial original para 11,6 $\mu \mathrm{m}$ após o tratamento com sol-gel. Embora aparentemente a alteração superficial
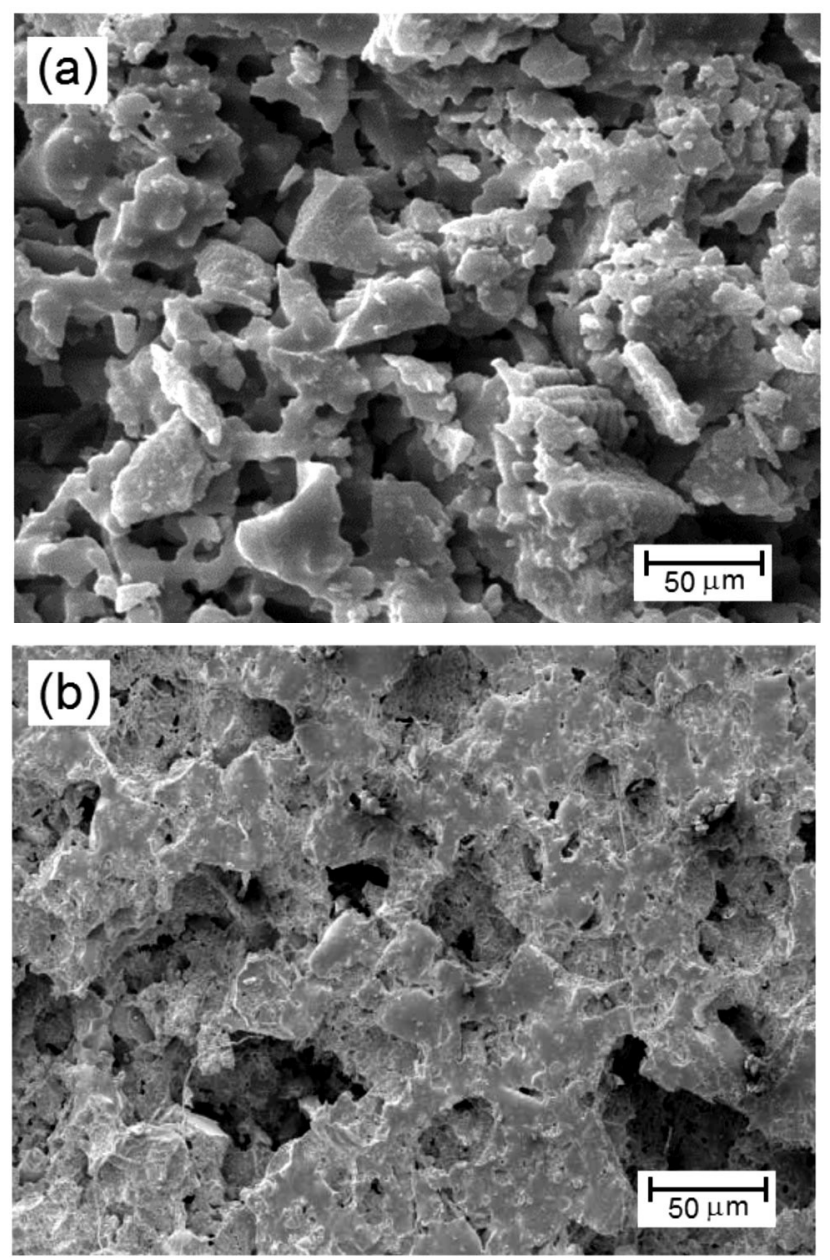

Figure 3: Micrografias MEV da (a) vela anterior e (b) posterior ao depósito de $\mathrm{SiO}_{2}$, calcinado segundo ciclo térmico apresentado na Fig. 1.

[Figure 3: SEM micrographs of (a) the filter before and (b) after $\mathrm{SiO}_{2}$ deposition calcined according to the thermal cycle shown in Fig. 1.]
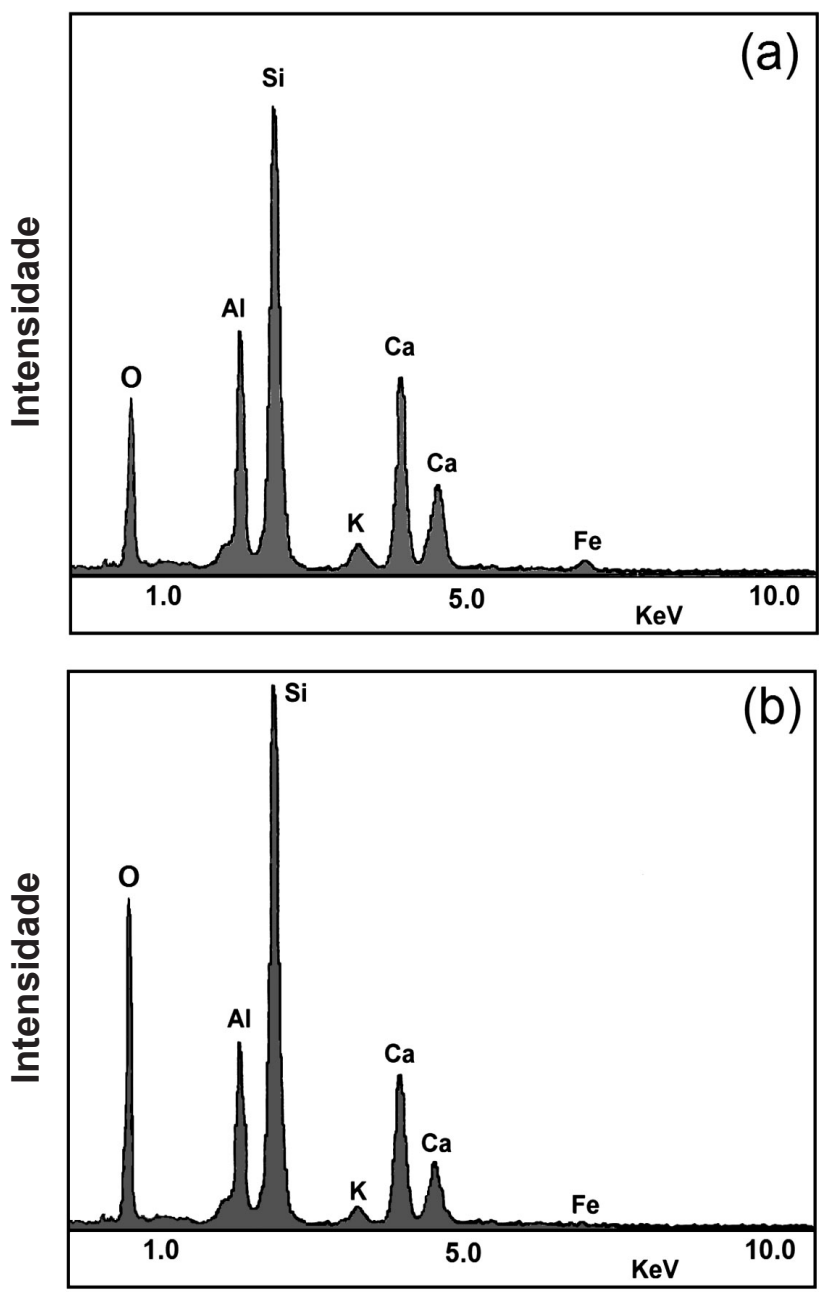

Figura 4: Espectro semiquantitativo de EDX para o substrato de vela cerâmica comercial anterior (a) e posterior (b) a deposição de filme de $\mathrm{SiO}_{2}$.

[Figure 4: EDX semiquantitative spectrum referred to substrate (a) and to the glass formed on the surface of the filter $(b)$.]

seja bastante significativa (Fig. 3) temos que no volume a porosidade se mantém, com uma pequena redução média (de aproximadamente 3,5 $\mu \mathrm{m}$ ), nos diâmetros de poros, indicando que a deposição ocorre predominantemente na superfície e menos intensamente no interior da matriz. Temos assim, de acordo com as medidas, um deslocamento da distribuição de tamanhos com estreitamento na frequência para poros de dimensões ligeiramente menores (Fig. 5). Cabe salientar que a redução de diâmetros de 15,2 para 11,6 $\mu \mathrm{m}$ não representam uma barreira significativa no processo de microfiltração. Contudo, este efeito causa uma ligeira queda de pressão com redução da permeação em função da velocidade do fluído conforme dados apresentados na Fig. 6. A queda é mais significativa para maiores velocidades indicando uma redução no fluxo permeado para um mesmo intervalo de tempo, mas sem impedimentos significativos para usos regulares aos quais foram inicialmente destinados esses elementos.

É importante observar, que embora seja confirmada uma redução nas dimensões dos poros, estes ainda são 


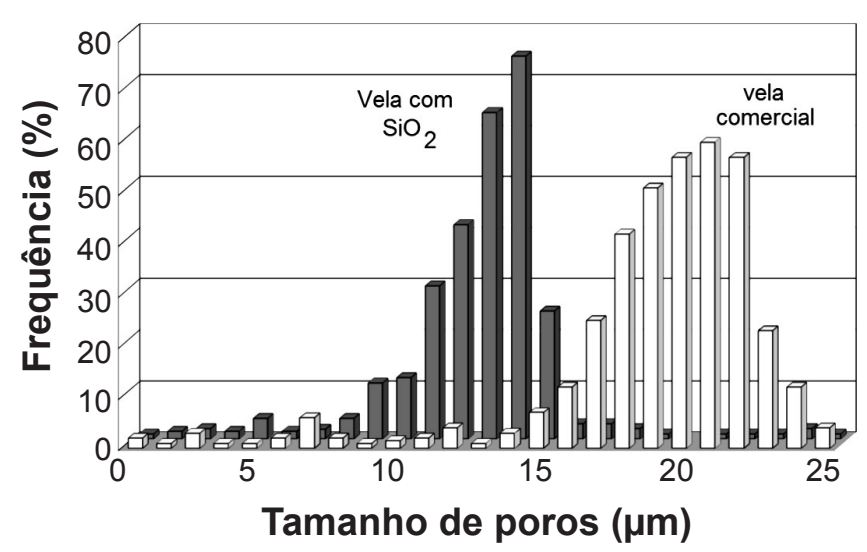

Figura 5: Distribuição de tamanhos de poros em amostra de vela de filtro com e sem filme de $\mathrm{SiO}_{2}$. Histograma montado com base nos dados obtidos em análise de porosimetria por intrusão de mercúrio. [Figure 5: Pore-size distributions for the candle with and without $\mathrm{SiO}_{2}$ film. Histogram set on bases of the mercury intrusion porosimetry data.]

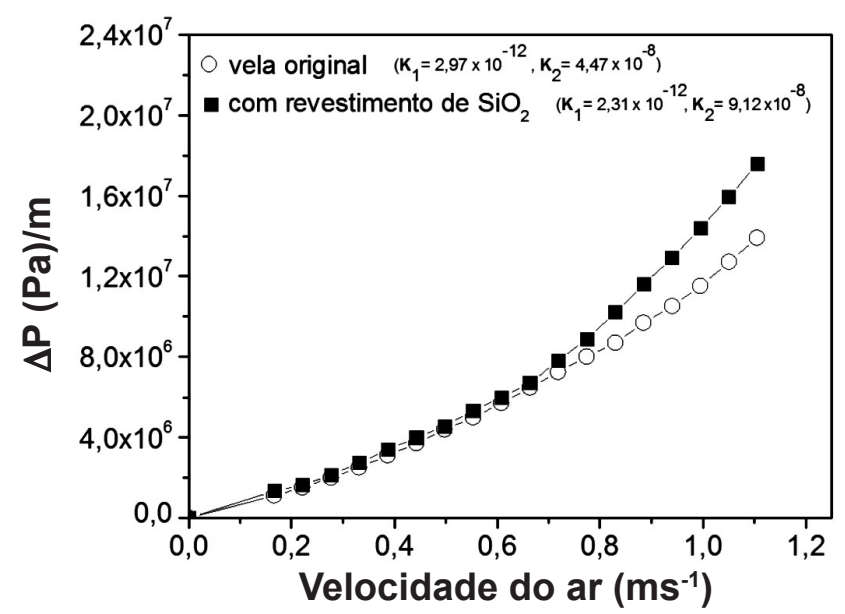

Figura 6: Valores de $\Delta \mathrm{P}$ (queda de pressão) em função da velocidade do ar para a vela em suas condições originais e após a calcinação de $\mathrm{SiO}_{2}$, para a qual é observada ligeira queda de pressão (redução da permeação). $\mathrm{K}_{1}$ se refere a constante de permeabilidade Darciana e $\mathrm{K}_{2}$ a região não-Darciana da curva.

[Figure 6: Plotted data of $\Delta P$ (pressure-drop) in function of air velocity for the samples tested. A slightly pressure drop (permeation reduction) is observed for $\mathrm{SiO}_{2}$ deposited surface. $K_{1}$ refers to Darcian permeability constant and $K_{2}$ to non-Darcian region of the curve.]

consideravelmente grandes para permitir que contaminantes orgânicos não sejam retidos e facilmente permeiem o meio.

\section{Testes de Filtragem}

Os testes de filtragem foram conduzidos em ambiente estéril, cujos resultados estão expressos na Fig. 7. A preparação do meio com grande número de bactérias seguiu procedimento padrão conforme descrito na literatura [16], sendo as filtrações conduzidas quando o número de colônias de Escherichia coli atingia seu máximo crescimento (máxima densidade ótica proporcional) no afluente. Para uma vela em sua condição normal vemos que a capacidade de retenção de bactérias decresce exponencialmente com o aumento da vazão. Esta apresenta razoável eficiência de retenção para baixas taxas de permeação (até aproximadamente $4 \mathrm{~mL} / \mathrm{min}$ ), com perda da capacidade de retenção para fluxos superiores. Por sua vez, a vela tratada apresenta um comportamento de decaimento de retenção linear, mantendo boa eficiência para fluxo até próximos a $12 \mathrm{~mL} / \mathrm{min}$. Para fluxos elevados, ambos materiais apresentam baixa eficiência com insignificante retenção do contaminante. Cabe salientar que o fluxo de 2 $\mathrm{mL}$ corresponde a um gotejamento de aproximadamente 10 gotas de $0,45 \mathrm{~mL} / \mathrm{min} . \mathrm{cm}^{2}$, de área permeável. O que é muito próximo às condições de filtração real em fluxo contínuo de uma vela em uma talha cerâmica doméstica [6].

A bactéria $E$. coli é um micro-organismo de forma bacilar, ou seja, tem o formato de um bastão achatado com dimensões típicas de $0,5 \mu \mathrm{m}$ de altura por $2 \mu \mathrm{m}$ de comprimento e com múltiplos flagelos o que possibilita alta mobilidade em meio aquoso. As dimensões da $E$. coli são consideravelmente menores que os tamanhos médios de poros, com livre deslocamento em ambos os meios testados. Assim, a filtração medida se dá predominantemente pela mobilização e retenção na superfície vítrea caracterizando assim o efeito de organofilicidade proporcionada pelo filme vítreo depositado.

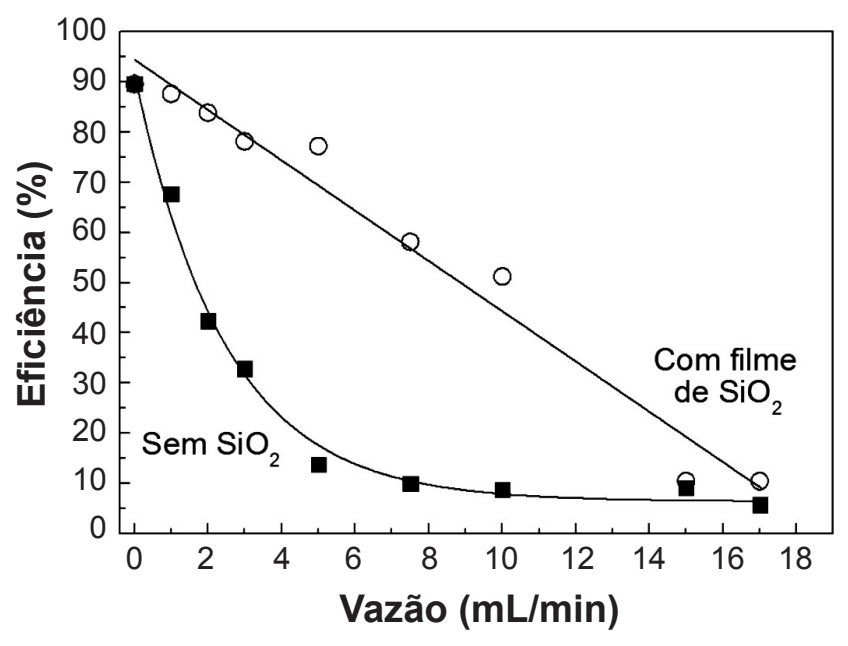

Figura 7: Eficiência de filtragem de E. Coli segundos dados de densidade ótica. Para baixas vazões é acentuada a remoção em função do aumento da organofilicidade do filme de vidro. Os valores se aproximam para maiores volumes.

[Figure 7: E. coli filtration efficiency in function of influent flux, according to optical density analysis. For low flows the bacteria removal is enhanced on treated sample due to increase of surface organophilicity. The data converge for both materials at higher flows volume.]

\section{CONCLUSÕES}

O uso do processo sol-gel para a formação de superfície vítrea a partir de solução precursora de tetrametoxisilano mostrou-se técnica viável para o aumento da organofilicidade 
de velas de filtração domestica. Nos testes realizados em elementos filtrantes comerciais a deposição de $\mathrm{SiO}_{2}$ gerou alterações superficiais decorrentes da formação de uma fina camada vítrea. Embora estas alterações tenham causado uma pequena redução da permeabilidade em função da diminuição dos tamanhos de poros, nos ensaios de filtração conduzidos para a remoção de bactérias E.coli em meio aquoso, o material tratado apresentou eficiências superiores em um maior intervalo de vazão do permeante. Evidentemente, em função do custo dos reagentes a técnica de sol-gel pode, no momento, não ser uma metodologia plenamente viável para emprego em larga escala, mas os resultados comprovam a sua eficiência na formação de uma superfície com maior organoficilidade, e em particular na interação com bactérias do tipo gram-positiva, podendo ser útil e viável para aplicações específicas.

\section{AGRADECIMENTOS}

Os autores agradecem os auxílios financeiros e bolsas concedidas por FAPESP, CNPq e Embrapa (RedeAgronano).

\section{REFERÊNCIAS}

[1] Organização Pan-Americana de Saúde (OMS): Política de Saneamento Ambiental como uma Política Pública Social, In: < http://www.opas.org.br>. Acesso em 03.04.2012.

[2] OMS: Água contaminada mata 2 milhões de pessoas por ano no mundo, In: <http://www.vermelho.org.br/ noticia.php?id_secao $=10 \& i d \_n o t i c i a=158002>$. Acesso em 04.04.2012.

[3] A. S. D. Gutierrez, Inf. Econ. 27 (1997) 5-7.

[4] OMS: Água e saúde - Brasil, 2001, In: <http://www.opas. org.br/sistema/fotos/agua.pdf $>$. Acesso em 05.04.2012.

[5] M. P. Souza, Instrumentos de gestão ambiental: Fundamentos e prática, Editora Riani Costa, S. Carlos, SP, (2000) $112 \mathrm{p}$.

[6] D. B. Purchas, K. Sutherland, Handbook of filter media, $2^{\mathrm{a}}$ Ed., Elsevier Sci. Inc., Oxford, UK (2002) 572p.

[7] O. B. G. Assis, C. R. Alves, F. C. Crnkovic, Filtros domésticos: o que eles filtram? J. Primeira Pág., S. Carlos, SP (30 Maio 1999) C2.

[8] O. B. G. Assis, L. G. Paterno, Cerâmica 57, 344 (2011) 422-427.

[9] M. M. Atabaki, R. Jafar, J. Idris, MJoM 16 (2010) 149163.

[10] P. Li, K. Groot, J. Sol-Gel Sci. Technol. 2 (1994) $797-$ 801.

[11] R. A. Vasques, M. D. M. Innocentini, O. B. G. Assis, Rev. Fís. Apl. Instr. 14 (1999) 120-123.

[12] M. D. M. Innocentini, R. C. O. Romano, H. Schreurs, V. P. Rodrigues, J. R. Coury, R. G. Pileggi, Cerâmica 55, 336 (2009) 437-447.

[13] C. R. Alves, O. B. G. Assis, Acta Microscopica 8, suppl. A (1999) 319-320.

[14] M. A. Aegerter, M. Jafelici Jr., D. F. Souza, E. D. Zanotto (Eds.), Sol-Gel Science and Technology, World Scientific, Singapura (1989).

[15] L. P. Silva, M. H. R. Seleghim, O. B. G. Assis, World J. Microbiol. Biotechn. 26 (2010) 2089-2092.

[16] J. Sawbrook, E. F. Fritsch, T. Maniatis, Molecular clining: a laboratory manual, $2^{\text {nd }}$ Ed., Cold Spring Harbor Laboratory Press, N. York, EUA (1989) p. A1-A5.

[17] G. J. Tortora, B. R. Funke, C. L. Case, Microbiologia, $6^{a}$ Ed., Artmed, Porto Alegre, RS (2000) 827p.

[18] N. Kawabata, I. Fujita, T. Inoue, J. Appl. Polym. Sci. 60 (1996) 911-917.

[19] C. R. Alves, O. B. G. Assis, Key Eng. Mater. 189-91 (2001) 91-96.

[20] P. Chartier, Verre 3 (1997) 5-13.

[21] J. Zarzycki, J. Sol-Gel Sci. Technol. 8 (1997) 17-22.

[22] A. A. S. Alfaya, L. T. Kubota, Quim. Nova 25 (2002) 835-841.

[23] S. Sakka, Ed., Sol-Gel Science and Technology: Topics in Fundamental Research and Applications, Kluwer Acad. Publ., Norewell, EUA 3 (2003).

(Rec. 16/04/2012, Ac. 20/07/2012) 